\title{
Peningkatan Mutu Bibit Torbangun (Plectranthus amboinicus Spreng.) dengan Pemilihan Asal stek dan Pemberian Auksin
}

\author{
The Improvement of Torbangun ( Plectranthus amboinicus Spreng.) Seedling Quality By \\ Using Combination of Cutting Methods and Auxin Concentration
}

Pipin Apriani ${ }^{1}$ dan M. Rahmad Suhartanto ${ }^{1 *}$

Diterima 5 Mei 2015 / Disetujui 2 Juli 2015

\begin{abstract}
Torbangun or Bangun-bangun (Plectranthus amboinicus), is an indigenous plant. Its leaves is used as herbal plant. Torbangun propagation is done vegetatively by cutting. The purpose of this research was to determine the best combination of cutting method and auxin concentration, in order to achieve vigorous seedlings. This research was conducted at Biofarmaka, IPB, from January until March 2014. It consisted of 2 experiments arranged in Completely Randomized Block Design. First experiment consisted of 3 kinds of cuttings and 3 kinds of auxin concentrations as treatments. Second experiment was continuation of the first experiment. Second experiment consisted of 3 kinds of bud cutting length and 3 kinds of auxin concentrations as treatments. The result of this research showed that the best cutting treatments was cutting of $7.0 \mathrm{~cm}$ in length. All concentrations of auxin did not affect to cutting's variables.
\end{abstract}

Keywords: cutting methods, seed quality, Plectranthus amboinicus

\begin{abstract}
ABSTRAK
Torbangun atau Bangun bangun (Plectranthus amboinicus) adalah tanaman indigenous yang daunnya dapat digunakan sebagai tanaman obat. Perbanyakan tanaman torbangun masih dilakukan secara vegetatif, yaitu menggunakan stek batang. Tujuan penelitian ini adalah untuk mendapatkan asal stek dan konsentrasi auksin yang tepat sehingga menghasilkan stek yang vigor. Penelitian ini telah dilaksanakan pada bulan Januari sampai dengan Maret di Biofarmaka, IPB. Penelitian ini terdiri atas 2 percobaan dan menggunakan rancangan kelompok lengkap teracak faktorial. Percobaan 1 memiliki 2 faktor perlakuan, yaitu asal stek dan konsentrasi auksin. Percobaan 2 terdiri atas 2 faktor perlakuan, yaitu panjang stek dan konsentrasi auksin. Hasil analisis data mulai minggu ke 3 sampai dengan minggu ke 7 setelah tanam menunjukkan bahwa stek asal pucuk dengan panjang 7 $\mathrm{cm}$ adalah stek yang paling baik untuk digunakan. Konsentrasi auksin pada ke dua percobaan tidak berpengaruh nyata pada semua tolok ukur keberhasilan stek torbangun.
\end{abstract}

Kata kunci: metode stek, mutu bibit, Plectranthus amboinicus

\section{PENDAHULUAN}

Sayuran indigenous merupakan bagian dari keanekaragaman hayati yang dimiliki Indonesia. Indonesia termasuk dalam 3 negara mega keanekaragaman hayati setelah Brazil dan Madagaskar (Baihaki, 2003). Sayuran indigenous dapat dijadikan sebagai diversifikasi komoditas hortikultura, namun perhatian terhadap sayuran indigenous masih kurang, bahkan cenderung ditinggalkan. Akibatnya, beberapa sayuran indigenous kurang dikenal dan mulai terancam punah. Torbangun (Plectranthus amboinicus) merupakan sayuran indigenous yang berpotensi untuk dikembangkan. Daunnya dapat dimanfaatkan sebagai obat herbal terutama untuk meningkatkan air susu ibu (ASI). Sejauh ini penelitian mengenai torbangun masih sebatas farmakologi sehingga

\footnotetext{
${ }^{1}$ Departemen Agronomi dan Hortikultura, Fakultas Pertanian, Institut Pertanian Bogor

(Bogor Agricultural University), Jl. Meranti, Kampus IPB Darmaga, Bogor 16680, Indonesia

Telp.\&Faks.62-251-8629353.*Email korespondensi: tantosuhartanto12@yahoo.co.id
} 
pemanfaatan torbangun masih pada daerah tertentu saja.

Ketersediaan bibit menjadi faktor penting agar masyarakat luas dapat dengan mudah memanfaatkan torbangun. Perbanyakan torbangun secara umum masih dilakukan secara vegetatif dengan menggunakan stek batang. Metode stek torbangun yang tepat sangat diperlukan untuk menghasilkan bibit dengan vigor tinggi, yaitu bibit bermutu dalam jumlah banyak dan seragam. Tersedianya bibit torbangun secara tidak langsung juga ikut melestarikan plasma nutfah dan mempermudah proses pelaksanaan penelitian yang berhubungan dengan pengembangan tanaman torbangun lebih lanjut.

Stek batang dapat dibagi menjadi 4 kelompok berdasarkan tipe jaringannya, yaitu hardwood, semihardwood, softwood dan herbaceous (Ashari, 2006). Stek torbangun termasuk ke dalam stek herbaceous dan asal stek torbangun dapat dibedakan menjadi 3 bagian, yaitu stek asal pucuk, stek asal batang bagian tengah dan stek asal pangkal. Pemilihan asal stek yang tepat adalah salah satu metode perbanyakan stek yang secara teknis sederhana untuk dilakukan. Sampai saat ini belum diketahui asal stek torbangun bagian mana yang mampu menghasilkan bibit torbangun dengan vigor tinggi. Semua asal stek torbangun diharapkan dapat menghasilkan bibit bervigor tinggi yang sama, sehingga tidak ada bagian tanaman yang terbuang. Yusmaini (2009) melaporkan bahwa stek asal pucuk memberi pengaruh nyata terhadap kemampuan hidup dan berakar paling tinggi dibandingkan stek bagian tengah dan pangkal pada vigor stek stevia (Stevia rebaudiana). Cara tanam yang berbeda, asal stek, dan ukuran stek dengan jumlah buku yang berbeda dapat meningkatkan produksi tanaman kumis kucing (Rahmania dan Kurniawati, 2014).

Usaha lain yang dapat dilakukan untuk menghasilkan bibit torbangun bervigor tinggi adalah dengan memberikan zat pengatur tumbuh (ZPT) auksin. Kandungan auksin mempengaruhi kemampuan batang untuk berakar. Rootone-F merupakan salah satu merk dagang zat pengatur tumbuh yang biasa digunakan sebagai sumber auksin pada proses penyetekan. Manurung (1987) menyatakan bahwa Rootone-F terdiri atas 1-naphtaleneacetamide (NAD), 2-methyl-1-naphtalene-acetic acid (MNAA), 3-methyl-1-naphtalene-acetamide
(MNAD), indole-3-butiric acid (IBA), dan stetramethyl-thiuram disulfide (Thiram).

Konsentrasi ZPT auksin yang dibutuhkan pada setiap tanaman tidak sama, sehingga penentuan konsentrasi dalam jumlah yang tepat pada tanaman torbangun sangat diperlukan untuk memberikan hasil yang optimum. Hartmann dan Kester (2002) menyatakan pada umumnya konsentrasi auksin yang digunakan berkisar antara $20 \mathrm{ppm}$ untuk spesies yang mudah berakar dan 200 ppm untuk spesies yang sulit berakar.

Penelitian ini bertujuan untuk meningkatkan mutu bibit torbangun melalui pemilihan asal stek torbangun dan konsentrasi zat pengatur tumbuh auksin yang paling tepat.

\section{BAHAN DAN METODE}

Penelitian berlangsung pada tanggal 31 Januari 2014 sampai dengan 26 Maret 2014 di Unit Konservasi dan Budi Daya Biofarmaka (UKBB) Cikabayan, IPB, Dramaga, Bogor. Bahan penelitian yang digunakan dalam penelitian ini adalah tanaman torbangun yang telah berumur kurang lebih 1.5 bulan yang diperoleh dari UKBB, IPB, Furadan 3G, ZPT auksin yaitu Rootone-F, polibag, media tanam berupa campuran tanah dan pupuk kandang dengan perbandingan (1:1) dan fungisida (Dithane M-45) serta paranet dengan kerapatan $50 \%$. Alat-alat yang digunakan selama penelitian, antara lain; gunting stek, gembor, dan alat ukur.

Penelitian ini terdiri atas 2 percobaan. Semua percobaan menggunakan rancangan kelompok lengkap teracak (RKLT) faktorial dengan 2 faktor. Percobaan 1 menggunakan asal stek (S) sebagai faktor pertama, yaitu stek asal pucuk (S1), stek asal tengah (S2) dan stek asal pangkal (S3). Masing-masing stek memiliki panjang yang sama yaitu $7 \mathrm{~cm}$. Faktor kedua adalah penggunaan Rootone-F dengan konsentrasi 0 ppm (K0), 20 ppm (K2) dan 40 ppm (K4).

Hasil Percobaan 1 dilanjutkan pada Percobaan 2. Percobaan 2 bertujuan untuk memperlajari lebih mendetail mengenai stek asal pucuk. Stek asal pucuk dibedakan lagi menurut panjang steknya. Panjang stek asal pucuk yang digunakan antara lain; $3.5 \mathrm{~cm}$ (P1), $7 \mathrm{~cm}$ (P2) pada Percobaan 1 dan $10.5 \mathrm{~cm}$ (P3). Faktor kedua Percobaan 2 sama halnya seperti Percobaan 1. 
Terdapat 9 kombinasi perlakuan dan setiap perlakuan diulang 3 kali. Masingmasing unit percobaan terdiri atas 10 tanaman. Terdapat 27 unit percobaan. Data hasil pengamatan diuji dengan uji-F dan hasil yang berpengaruh nyata dilakukan uji lanjut Duncan Multiple Range Test (DMRT) pada taraf $\alpha=5 \%$.

Metode pelaksanaan penelitian dimulai dengan persiapan lahan dan media tanam. Lahan yang dibersihkan dan dibagi menjadi 3 bagian. Kemudian lahan dipasangi paranet dengan kerapatan 50\%. Polibag diisi dengan media tanam, yaitu tanah dan pupuk kandang dengan perbandingan volume $(1: 1)$, lalu diletakkan dan dibagi menjadi 3 ulangan. Setiap ulangan terdiri dari 150 polibag. Selanjutnya, persiapan bahan tanam, pengambilan bahan stek dilakukan pada pagi hari. Batang tanaman torbangun khusunya bagian masing-masing asal stek dipotong miring $\left( \pm 45^{0}\right)$ pada bagian dasar. Stek yang tidak diberi perlakuan Rootone F (kontrol) segera ditanam dengan dengan membenamkan kurang lebih $\pm 1.5 \mathrm{~cm}$ ke dalam media. Jumlah daun disisakan pada asal stek pucuk dan tengah yaitu 4 daun. Pemberian Furadan dilakukan bersamaan dengan penanaman. Setelah itu, dilakukan penyiraman agar stek tetap segar.

Larutan Rootone F 20 ppm dan 40 ppm disiapkan setelah bahan tanam selesai. Larutan dibuat sebanyak 3 kali ulangan. Stek yang telah siap, dicelupkan secara cepat ke larutan Rootone F sekitar 3 detik lalu segera ditanam dan diberi furadan. Setelah itu, penyiraman dilakukan secukupnya agar stek tetap segar. Pembibitan torbangun dipelihara secara intensif dengan penyiraman setiap hari jika tidak hujan. Penyemprotan fungisida dilakukan saat telah mencapai ambang batas ekonomi. Penyiangan gulma dilakukan setiap minggu. Pengamatan dilakukan sejak 3 Minggu Setelah Tanam (MST) sampai dengan tanaman berusia 7 MST.

Variabel yang diamati selama percobaan yaitu sejak 3 MST - 7 MST

1. Persentase stek hidup (\%), dengan menghitung perbandingan jumlah stek hidup pada akhir pengamatan dengan jumlah stek yang ditanam. Pengamatan dilakukan saat 7 MST.

2. Persentase stek berakar (\%), dengan menghitung perbandingan jumlah stek berakar dengan jumlah stek yang ditanam. Pengamatan dilakukan saat 7 MST.
3. Jumlah akar, dengan menghitung semua akar yang muncul, dilakukan pada akhir pengamatan (7 MST).

4. Panjang akar $(\mathrm{cm})$, diukur dari pangkal (leher akar) sampai ujung akar pada akar utama pada akhir pengamatan (7 MST).

5. Tinggi stek $(\mathrm{cm})$ pada Percobaan 1, diukur dari permukaan tanah sampai ujung pucuk tertinggi, dilakukan setiap minggu mulai 3MST - 7 MST.

6. Pertambahan jumlah daun (daun/minggu) pada Percobaan 1, dihitung dengan cara hasil pengurangan (jumlah daun pada akhir pengamatan - jumlah daun saat penanaman) dibagi lamanya pengamatan dalam satuan minggu.

7. Kecepatan tumbuh ( $\mathrm{cm} /$ minggu $)$ pada Percobaan 2, dihitung dengan rumus :

\section{Kec.Tumbuh $=\underline{\text { Tinggi Awal }(\mathrm{cm})-\text { Tinggi Akhir }(\mathrm{cm})}$ Lama Pengamatan ( Minggu)}

8. Jumlah daun pada Percobaan 2, dihitung dengan jumlah daun yang telah membuka sempurna. Dilakukan setiap minggu mulai 3 MST - 7 MST.

\section{HASIL DAN PEMBAHASAN}

\section{Kondisi Umum}

Stek torbangun menunjukkan pertumbuhan yang cukup cepat sejak 3 MST. Kendala yang dialami adalah tanah yang lembab karena curah hujan tinggi menyebabkan stek dan media mudah terinfeksi sehingga stek torbangun mudah busuk. Pemasangan paranet di lapangan berguna untuk menghindari stek terkena hujan secara langsung. Kegiatan penyiraman juga dikurangi menjadi sehari sekali atau tidak melakukan penyiraman jika hujan. Menurut BMKG (2014) tercatat bahwa curah hujan di Dramaga mencapai $337 \mathrm{~mm}$ pada bulan Februari, curah hujan menurun menjadi 281 $\mathrm{mm}$ pada bulan maret.

Sek torbangun terserang penyakit hawar daun mulai umur tanaman 5 MST sehingga dilakukan penyemprotan Dithane pada media tanam. Serangan hama yang ditemui adalah rayap (Macrotermes gilvus Hagen) yang berpengaruh terhadap hasil percobaan. Pengendalian hama dilakukan dengan cara memberi Furadan kembali. 
Tabel 3. Pengaruh asal stek terhadap tolok ukur keberhasilan perakaran pada umur $7 \mathrm{MST}^{\mathrm{a}}$

\begin{tabular}{|c|c|c|c|}
\hline \multirow[t]{2}{*}{ Parameter } & \multicolumn{3}{|c|}{ Asal Stek } \\
\hline & Pucuk & Tengah & Pangkal \\
\hline Persentase Stek & & & \\
\hline Berakar (\%) & $88.9 \mathrm{a}$ & $76.7 \mathrm{a}$ & $20.0 \mathrm{~b}$ \\
\hline Jumlah Akar & $65.4 \mathrm{a}$ & $45.0 \mathrm{~b}$ & $13.6 \mathrm{c}$ \\
\hline $\begin{array}{l}\text { Panjang Akar } \\
(\mathrm{cm})\end{array}$ & $4.07 \mathrm{a}$ & $3.96 \mathrm{a}$ & $2.64 \mathrm{~b}$ \\
\hline angan: ${ }^{a} \mathrm{An}$ & & & $\begin{array}{l}\text { ama yans } \\
\text { ma tidal }\end{array}$ \\
\hline
\end{tabular}

Stek yang berasal dari pucuk memiliki perakaran yang lebih baik dibanding stek asal tengah dan stek asal pangkal. Hal ini terlihat dari persentase stek berakar, jumlah akar dan panjang akar yang lebih baik dibanding asal pangkal serta panjang akar lebih baik dibanding stek asal tengah pada akhir pengamatan yaitu 7 MST (Tabel 3). Akar yang dimiliki stek torbangun merupakan akar serabut sehingga kurang kuat perakarannya. Rendahnya jumlah akar stek pangkal diduga karena jaringan terlalu tua mempersulit proses tumbuhnya akar sehingga diperlukan perlakuan tambahan untuk menginisiasi akar, namun dalam penelitian ini pemberian zat pengatur tumbuh auksin tidak memberikan pengaruh nyata terhadap perakaran. Menurut Moko (2004) penurunan kemampuan berakar pada jaringan tua karena pada jaringan tua telah terbentuk jaringan schlerenchym yang sering menghambat inisiasi akar adventif.

Munculnya akar pada stek merupakan penentu tingkat keberhasilan proses penyetekan. Pemilihan asal stek yang tepat sangat penting karena mempengaruhi kecepatan tumbuh akar. Menurut Nurhayati (2000) banyaknya jumlah akar menyebabkan penyerapan hara dan air akan lebih optimal sehingga proses fisiologi akan berlangsung lebih baik untuk mengimbangi pertumbuhan dan perkembangan tunas.

Persediaan makanan berupa senyawa karbohidrat dan nitrogen untuk stek sangat diperlukan bagi pertumbuhan akar dan tunas. Pucuk umumnya mengandung $\mathrm{C} / \mathrm{N}$ lebih tinggi dibandingkan bagian stek lainnya. Menurut Agung (2010) bahan stek berupa batang dengan warna kulit bagian dalam terlihat kehijauan menandakan adanya kandungan auksin, nitrogen dan karbohidrat yang tinggi sehingga akan mempercepat timbulnya akar.

\section{Jumlah Tunas}

Variabel jumlah tunas diamati setiap minggu bertujuan untuk mengetahui perubahan jumlah tunas karena pembentukan tunas sangat penting antara lain untuk bahan stek berikutnya. Menurut Febriana (2009) pembentukan tunas sangat penting sebagai tahap awal pembentukan primordia daun dimana daun merupakan organ tanaman yang memiliki jumlah klorofil terbesar yang berfungsi sebagai tempat terjadinya proses fotosintesis untuk menghasilkan karbohidrat sebagai sumber makanan. Berdasarkan hasil uji Duncan saat 4 MST -7 MST pengaruh asal stek terhadap tolak ukur jumlah tunas dapat dilihat pada Tabel 4.

Stek yang berasal dari pucuk lebih banyak menghasilkan tunas dibandingkan asal stek tengah dan pangkal sejak umur 4 MST - 7 MST. Hal ini diduga setiap asal stek memiliki kandungan auksin yang berbeda-beda sehingga memiliki pengaruh yang berbeda-beda nyata terhadap pembentukan. Menurut Hartmann dan Kester (2002) tunas terbentuk akibat adanya proses morfogenesis yang menyangkut pertumbuhan dan diferensiasi oleh beberapa sel yang memacu terbentuknya organ. Munculnya tunas dipengaruhi oleh hormon endogen, salah satunya auksin.

Kandungan auksin pada bahan stek dapat ditingkatkan melalui pemberian hormon auksin sintesis. Pemberian Rootone-F pada semua taraf tidak memberikan pengaruh nyata, hal ini diduga karena konsentrasi yang diberikan belum optimal atau kandungan auksin telah terpenuhi oleh auksin endogen stek torbangun, sehingga tanpa auksin sintetis, stek torbangun masih dapat hidup.

Tabel 4. Pengaruh asal stek jumlah tunas ${ }^{\mathrm{a}}$

\begin{tabular}{cccc}
\hline Umur & \multicolumn{3}{c}{ Asal Stek } \\
\cline { 2 - 4 } (MST) & Pucuk & Tengah & Pangkal \\
\hline 4 & $2.8 \mathrm{a}$ & $2.1 \mathrm{~b}$ & $1.1 \mathrm{c}$ \\
5 & $2.3 \mathrm{a}$ & $1.4 \mathrm{~b}$ & $1.0 \mathrm{c}$ \\
6 & $2.9 \mathrm{a}$ & $2.4 \mathrm{~b}$ & $1.2 \mathrm{c}$ \\
7 & $2.9 \mathrm{a}$ & $2.2 \mathrm{~b}$ & $1.2 \mathrm{c}$ \\
\hline
\end{tabular}

Keterangan: ${ }^{a}$ Angka-angka pada baris yang sama yang diikuti oleh huruf yang sama tidak berbeda nyata pada taraf uji 5\% (uji selang berganda Duncan). 


\section{Pertambahan Tinggi dan Jumlah Daun}

Parameter tinggi tanaman dan jumlah daun diamati mulai minggu ke-3 setelah penanaman hingga akhir pengamatan (7 MST). Pengamatan yang dilakukan setiap minggu bertujuan untuk mengetahui pertambahan tinggi dan jumlah daun pada stek. Asal stek mampu meningkatkan tinggi tanaman dan jumlah daun yang dihasilkan pada stek torbangun hingga akhir pengamatan (7 MST). Asal stek pucuk mampu menghasilkan bibit torbangun yang paling tinggi yakni $22.65 \mathrm{~cm}$. Tinggi bibit torbangun yang berasal dari stek asal bagian tengah adalah $19.94 \mathrm{~cm}$ dan stek asal pangkal $16.41 \mathrm{~cm}$. Tinggi bibit sangat penting dalam perbanyakan stek sebab semakin tinggi bibit maka semakin banyak bahan tanam (stek) yang didapatkan.

Jumlah pertambahan daun per minggu untuk stek pucuk sebanyak 4 daun minggu ${ }^{-1}$, berbeda halnya dengan stek tengah dan stek pangkal yang mengalami pertambahan daun lebih sedikit dibandingkan stek pucuk yakni 3 daun minggu ${ }^{-1}$. Bappenas (1991) menyatakan bahwa daun merupakan bagian tanaman yang penting untuk menerima sinar matahari dan proses fotosintesis. Daun berguna untuk membangun jaringan dan memberikan energi pada tanaman. Sari (2002) menyatakan bahwa semakin banyak daun yang dimiliki semakin banyak pula fotosintat yang dihasilkan, yang berguna untuk mendukung pertumbuhan dan perkembangan tanaman itu sendiri.

\section{Stek Pucuk}

Tingkat ketersediaan bibit torbangun yang sehat dalam jumlah banyak dapat meningkatkan hasil produksi, namun kebutuhan tanaman torbangun yang dibutuhkan untuk bahan stek juga semakin banyak. Bahan stek torbangun masih dalam kondisi terbatas dan sejauh ini belum ada rekomendasi untuk panjang stek torbangun yang tepat. Berdasarkan hasil Percobaan 1, stek asal pucuk adalah asal stek yang paling baik untuk digunakan (Tabel 1-4), sehingga panjang stek asal pucuk torbangun yang efektif perlu diperoleh. Nilai rata-rata terhadap variablevariabel keberhasilan stek torbangun di umur 7 MST dapat dilihat pada Tabel 5.
Tabel 5. Rekapitulasi nilai rata-rata terhadap pengamatan variabel-variabel keberhasilan stek pada umur 7 MST

\begin{tabular}{|c|c|c|c|}
\hline \multirow[b]{2}{*}{ Parameter } & \multicolumn{3}{|c|}{ Perlakuan } \\
\hline & $\begin{array}{l}\text { Stek } \\
3.5 \\
\mathrm{~cm}\end{array}$ & $\begin{array}{l}\text { Stek } \\
7.0 \\
\mathrm{~cm} \\
\end{array}$ & $\begin{array}{l}\text { Stek } \\
10.5 \\
\mathrm{~cm}\end{array}$ \\
\hline Persentase Stek & & & \\
\hline Hidup (\%) & 81.1 & 88.9 & 82.2 \\
\hline Jumlah Tunas & 6.8 & 7.6 & 9.1 \\
\hline Persentase Stek & & & \\
\hline Berakar(\%) & 81.1 & 88.9 & 82.2 \\
\hline Jumlah Akar & 59.8 & 65.4 & 52.0 \\
\hline $\begin{array}{l}\text { Panjang Akar } \\
(\mathrm{cm})\end{array}$ & 3.2 & 4.07 & 4.7 \\
\hline $\begin{array}{l}\text { Kecepatan } \\
\text { Tumbuh } \\
\text { (cm/minggu) }\end{array}$ & 2.3 & 4.2 & 2.0 \\
\hline Jumlah Daun & 24.7 & 24.7 & 24.8 \\
\hline
\end{tabular}

Stek asal pucuk dengan panjang 7 dan $10 \mathrm{~cm}$ memiliki persentase stek hidup, perakaran, jumlah tunas dan jumlah daun yang lebih banyak dibandingkan stek asal pucuk dengan panjang $3.5 \mathrm{~cm}$. Hal ini diduga panjang stek 7 dan $10.5 \mathrm{~cm}$ masih memiliki kandungan karbohidrat yang optimum. Magingo dan Dick (2001) menyatakan bahwa pertumbuhan akar pada stek batang dipengaruhi oleh kandungan karbohidrat dan panjang stek. Semakin panjang stek yang digunakan maka pertumbuhan panjang akarnya semakin baik karena lebih banyak cadangan makanan yang digunakan untuk mendukung pertumbuhan akarnya. Stek asal pucuk dengan panjang 10.5 $\mathrm{cm}$ memiliki panjang akar dan jumlah tunas lebih banyak dibandingkan panjang stek asal pucuk yang lain. Kecepatan tumbuh antar stek hampir sama.

\section{KESIMPULAN}

Stek yang berasal dari pucuk dengan panjang $7.0 \mathrm{~cm}$ adalah asal stek terbaik yang dapat digunakan sebagai bahan tanam. Stek asal pucuk mampu menghasilkan stek torbangun yang vigor berdasarkan komponen keberhasilan stek dan pertumbuhan stek. Stek yang berasal tengah adalah stek yang dapat digunakan sebagai bahan tanam setelah stek asal pucuk karena menghasilkan nilai variabel- 
variabel keberhasilan stek yang sama seperti stek asal pucuk kecuali jumlah akar, jumlah tunas dan pertumbuhan stek. Konsentrasi auksin sampai dengan $40 \mathrm{ppm}$ tidak mempengaruhi peningkatan mutu bibit torbangun.

\section{DAFTAR PUSTAKA}

Agung, S. 2010. Kunci Sukses Memperbanyak Tanaman. Agromedia Pustaka. Jakarta.

Ashari, S. 2006. Hortikutura Aspek Budi Daya. UI Pr. Jakarta.

Baihaki, A. 2003. Aspek sosial ekonomi dalam pemanfaatan dan pelestarian keanekaragaman hayati Jawa Barat. Ekologi dan Biodiversitas Tropika. 2(2): 54-60

Bappenas. 1991. Petunjuk Lapangan Latihan PHT Palawija. Fiat Panis. Yogyakarta.

Febriana, S. 2009. Pengaruh kosentrasi ZPT dan panjang stek terhadap pembentukan akar dan tunas pada stek apokad (Persea americana Mill.). Skripsi. Institut Pertanian Bogor. Bogor.

Hartmann, H.T., D.E. Kester. 2002. Plant Propagation, Principles and Practice. 7th ed. Prentice Hall, Inc.Engle Wood Cliff. New Delhi (IN).

Magingo, F.S., J.M. Dick. 2001. Propagation of two miombo woodland trees by leafy stem cuttings obtained from seedlings. Agroforestry System.1 (51): 49-55.

Manurung, S.O. 1987. Status dan potensi zat pengatur tumbuh serta penggunaan Rootone-F dalam perbanyakan tanaman pucuk gamelina (Gmelina arborea Linn). Skripsi. Institut Pertanian Bogor. Bogor.

Moko, H. 2004. Teknik Perbanyakan Tanaman Hutan Secara Vegetatif. Volume ke-1. Pusat Litbang Bioteknologi dan Pemuliaan Tanaman Hutan Informasi. Bogor.

Nurhayati, A.D. 2000. Pengaruh bahan stek dan Rootone-F terhadap pertumbuhan seuseureuhan (Piper aduncum Linn.). Skripsi. Institut Pertanian Bogor. Bogor.

Rahmania, R., A. Kurniawati. 2014. Penentuan ukuran stek kumis kucing (Orthosiphon aristatus Bl. Miq.) dan dosis pupuk dosis pupuk kandang pada cara tanam langsung. J. Hort. Indonesia 5(3) : 189-202.

Sari, L. 2002. Respon pertumbuhan stek batang sirih merah (Piper crocatum Ruiz dan Pav) setelah direndam dalam urin sapi. Protobiont. 2(5):157-160.

Yusmaini, F. 2009. Pengaruh jenis bahan stek dan penyungkupan terhadap keberhasilan dan vigor stek stevia (Stevia rebaudiana Bertoni M). Skripsi. Institut Pertanian Bogor. Bogor. 